\title{
ANÁLISE DA PRÁTICA PEDAGógICA E O DESENVOLVIMENTO DA ARGUMENTAÇÃO EM AULAS DE FÍSICA
}

\section{ANALYSIS OF PEDAGOGICAL PRACTICE AND THE DEVELOPMENT OF ARGUMENTATION IN PHYSICS CLASSES}

\author{
Juliana Rosa Alves Borges ${ }^{1}$ \\ Sandro Rogério Vargas Ustra ${ }^{2}$
}

\begin{abstract}
Resumo: A habilidade de argumentar é essencial ao cidadão contemporâneo. Apesar de trabalhada de forma pouco criteriosa em sala de aula, apresenta papel central no processo de aprendizagem em Física. Destarte, nosso propósito principal neste estudo foi apurar aspectos relevantes no desenvolvimento da argumentação no ambiente do Ensino por Investigação em aulas de Física. A pesquisa de natureza qualitativa utilizou princípios da pesquisa-ação tendo como alvo uma melhor qualidade para a interação professor/aluno. As atividades didáticas foram desenvolvidas em grupos pelos estudantes e o processo de investigação contou com a monitoria docente. Os dados foram coletados no diário da prática pedagógica, utilizando-se para sua compreensão elementos da Análise de Conteúdo. Destacamos a consolidação do protagonismo estudantil e da qualidade argumentativa nesse contexto do Ensino por Investigação.
\end{abstract}

Palavras-chave: Argumentação; Ensino de Física; Ensino por Investigação.

Abstract: The ability to debate is an essential quality for the contemporary citizen. Although worked in a non-judicious way in the classroom, it plays a central role in the Physics learning process. Our main purpose in this research was to investigate the relevant aspects in argumentation development in the Teaching per Inquiry environment in physics classes. In this qualitative research, we used research-action principles having as purpose a better teacher/student interaction. There were applied didactic activities in the students group and the investigation process included monitoring by the teacher. Data were collected in the pedagogical practice diary, using elements of Content Analysis for their understanding. We highlight the consolidation of the students'protagonism and of the argumentative quality in this context on Teaching per Inquiry.

Keywords: Argumentation; Physics teaching; Teaching per Inquiry.

\section{Introdução}

As políticas educacionais brasileiras para a Educação Básica defendem a formação integral do educando. Os documentos oficiais apontam a necessidade da aproximação dos conteúdos escolares às questões cotidianas. A principal justificativa é a

\footnotetext{
${ }^{1}$ Mestre em Educação, Universidade Federal de Uberlândia (UFU), Universidade Federal de Uberlândia (UFU), Uberlândia, Minas Gerais, Brasil. E-mail: julianalvesborg@hotmail.com.

${ }^{2}$ Doutor em Educação, Universidade de São Paulo (USP), Universidade Federal de Uberlândia (UFU), Uberlândia, Minas Gerais, Brasil. E-mail: srvustra@ufu.br.
} 


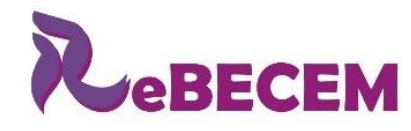

DOI: https://doi.org/10.33238/ReBECEM.2021.v.5.n.1.26090

preparação para o pleno exercício da cidadania, entendida como a consciência dos direitos civis, políticos e sociais, mediante participação responsável no contexto em que o sujeito atua.

O ensino de Ciências, e de Física em particular, é fundamental nesse contexto. Seus conteúdos estão relacionados a questões científicas, sociais, tecnológicas e ambientais, podendo contemplar uma perspectiva crítica do cotidiano, aliada à sua compreensão e transformação. Assim como as demais disciplinas na Educação Básica, sua principal função é contribuir para a emancipação dos alunos, favorecendo seu desenvolvimento cognitivo e pessoal fora dos portões da escola.

Na sociedade atual, o cidadão preparado não é aquele que apenas reproduz a partir de um modelo pronto, mas o que se posiciona, considera distintas perspectivas, critica e age de forma coerente com sua realidade, contribuindo para uma coletividade melhor. Destarte, vale destacar a importância da contextualização dos conteúdos disciplinares da Física a fim de promover a responsabilidade social e ética mediante pesquisa e argumentação sobre os tópicos trabalhados na escolarização (MALACARNE, STRIEDER, LIMA, 2011).

Ou seja, as concepções contemporâneas de educação concedem destaque ao desenvolvimento das habilidades de pensamento crítico, como argumentar, analisar e inferir. Sendo assim, imprescindível o domínio da linguagem que se aplica em diferentes contextos. À vista disso, torna-se imperativo o uso de estratégias didáticas capazes de proporcionar aos alunos aprendizado consoante a essas expectativas.

Ultimamente, essa percepção sobre o papel da linguagem na concretização de competências e habilidades tem norteado práticas educativas no sentido de identificar valores e princípios da pesquisa científica com alvos no agenciamento do debate e da argumentação. O envolvimento de estudantes em atividades estruturadas com foco no discurso e na investigação é exitoso na ampliação do entendimento sobre a ciência e suas linguagens e direcionam o fazer e o aprender científicos (DUSCHL; OSBORNE, 2002).

Perante o exposto, defende-se neste estudo uma relação dialógica entre professor e aluno, bem como, uma pedagogia relacional que se articula com a epistemologia construtivista. O propósito principal da pesquisa desenvolvida no âmbito da própria prática docente da professora pesquisadora, também autora deste artigo, consistiu em compreender aspectos relevantes no desenvolvimento da argumentação no ambiente do Ensino por Investigação em aulas de Física. Buscou-se, no contexto de atuação docente, 


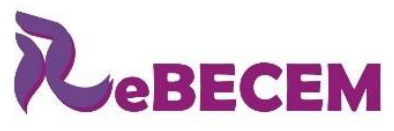

DOI: https://doi.org/10.33238/ReBECEM.2021.v.5.n.1.26090

alcançar a consolidação de práticas pedagógicas com tendência ao pensamento mais aberto e plural convergindo para uma proposta didática desafiadora que exige o rompimento de limites e a aplicação dos conteúdos escolares na vida diária.

O realce na habilidade argumentativa deveu-se à amplitude de seu significado em diversas áreas do conhecimento, particularmente no campo das Ciências Naturais, e também, ao fato de que a maioria dos discentes demonstra dificuldade em expressar claramente o conhecimento formal ou o que entende dele. Já o Ensino por Investigação é destacado por permitir ao aluno não apenas o acesso ao conhecimento científico, mas a compreensão de como se produz ciência e qual a natureza de seus conhecimentos e sistemas de institucionalização. Essas duas ênfases corroboram para a participação ativa do estudante em todas as etapas pedagógicas previstas no processo de ensinoaprendizagem planejado pela professora pesquisadora.

\section{A argumentação na escola e suas contribuições para a formação do educando}

Muitas ações realizadas no ambiente escolar nas diferentes disciplinas envolvem a argumentação. Mas o que é argumentação? Qual é a sua importância no ensino de Física? Para responder a essas questões ressalta-se que seu conceito ainda abrange inconsonâncias; contudo, a argumentação é parte constituinte e essencial da prática científica. Ela está presente em todas as etapas de uma pesquisa, podendo acontecer em diferentes níveis de multiplicidade, de acordo com o ambiente, os objetivos e a comunidade compreendida (DRIVER; NEWTON; OSBORNE, 2000).

Neste estudo adotaremos a argumentação como uma articulação de ideias que tem por objetivo convencer os interlocutores e/ou apresentar pontos de vista com o fim de contribuir para o entendimento mais amplo de determinado fenômeno. Tal atividade inclui pesquisa, conhecimento, habilidades discursivas, raciocínio lógico, autonomia crítica, portanto, se relaciona intimamente à epistemologia da Ciência.

A capacidade de argumentar se amplia no exercício contínuo, e assume especial significado quando os sujeitos tomam consciência da de sua função na construção de conhecimentos e valores. Costa (2008) ressalta que o uso do argumento não é uma habilidade inerente aos estudantes, mas um processo vivenciado na prática em sala de aula. O incentivo ao emprego de explicações e a arguição de pontos de vistas conectados 
DOI: https://doi.org/10.33238/ReBECEM.2021.v.5.n.1.26090

aos fenômenos estudados institui condição adequada ao seu desenvolvimento. O êxito dos resultados obtidos e a prontidão dos alunos ao aderirem a essa proposta são diretamente proporcionais à precocidade no estímulo da construção do argumento por parte do docente (MONTEIRO, 2002).

As práticas argumentativas têm encontrado vasto campo de pesquisa na área do Ensino de Ciências (SÁ; QUEIROZ, 2011). Suas contribuições à aprendizagem são ampliadas, significativamente, ao contemplar questões sociocientíficas, através das quais os estudantes podem estabelecer relações importantes entre os conteúdos conceituais e atitudinais que lhes permitem uma compreensão e atuação mais críticas em seu meio social. A multiplicidade de perspectivas das questões sociocientíficas implica em oposição entre as opiniões dos envolvidos, favorecendo o exercício da argumentação de forma coerente com os conteúdos envolvidos (CORREIA; DECIAN; SAUERWEIN, 2017).

Scarpa, Sasseron e Silva (2017) retratam o valor do estímulo à leitura, estabelecimento de relações entre variáveis, interpretações, inferências, refutações/ou adoção de hipóteses e contextualização dos saberes escolares permitindo que o aluno perceba sua utilidade rotineira. Elas identificam esses feitos, essenciais no desenvolvimento da habilidade argumentativa, como componentes de um estímulo extra para o professor que pretende proporcionar ao aluno conhecimento autêntico capaz de exceder ao entendimento de um conceito específico.

Em um breve histórico sobre o Ensino por Investigação (EI), Ferraz (2015) observou que as revisões curriculares ocorridas ao longo dos anos provocaram mudanças em seus objetivos. A partir da década de 1990, buscou-se a extensão de atribuições da cultura científica, suas linguagens, tecnologias e seus impactos na natureza e sociedade. Obteve-se então a idealização de um corpo de conhecimento socialmente autenticado e correlacionado com a natureza da investigação científica.

Esta perspectiva reafirma a análise de Zômpero e Laburú (2011):

O ensino por investigação, que leva os alunos a desenvolverem atividades investigativas, não tem mais como na década de 1960 a finalidade de formar cientistas. Atualmente, a investigação é utilizada no ensino com outras finalidades, como o desenvolvimento da habilidade cognitiva dos alunos, a realização de procedimentos como a elaboração de hipóteses, anotação e análise de dados e o desenvolvimento da capacidade de argumentação (p. 73, grifo nosso). 


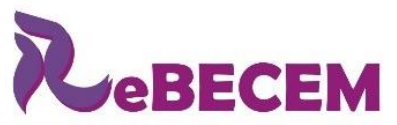

Revista Brasileira de Educação em

Ciências e Educação Matemática

DOI: https://doi.org/10.33238/ReBECEM.2021.v.5.n.1.26090

No EI, o desenvolvimento da argumentação encontra terreno propício, pois se tratam de construções coletivas, dialogadas, o que permite intervenções e incorporação de diferentes opiniões e saberes, a exemplo do que acontece na própria ciência. A problematização é o combustível das aulas e a pesquisa a trajetória percorrida para se chegar ao destino que não é preestabelecido dogmaticamente. A "solução" é uma incógnita que pode ser desvendada em um debate na sala de aula (ou outro ambiente), em uma busca virtual, no manejo de materiais pedagógicos, no estudo individual da temática, etc.

Clement (2013) reafirma a importância do Ensino por Investigação na participação intensa dos estudantes, no desenvolvimento da habilidade de resolução de problemas, de argumentação, na aquisição da autonomia intelectual e do pensamento crítico. Na perspectiva, destacam-se suas contribuições associadas à participação dos estudantes no processo de aprendizado, conferindo aos próprios, maior controle sobre a sua aprendizagem.

Logo, advoga-se um consenso metodológico entre EI e o desenvolvimento da argumentação, visto que ambos requerem do aluno uma postura ativa, bem como, aproxima professores e estudantes ao estabelecer parceria e modificar o modelo de aula praticado. Nos moldes do trabalho contemplado no presente estudo, o EI é implantado em grupos de estudantes beneficiando a aprendizagem colaborativa e favorecendo a socialização e troca de ideias.

\section{A estrutura do argumento}

Segundo Toulmin (2006, p. 136), um argumento é como um organismo: tem uma estrutura bruta, anatômica, e outra mais fina e, por assim dizer, fisiológica. A estrutura de um bom argumento não é única, pois depende do seu contexto de origem. Ele pode ser bastante singelo ou mais elaborado.

Em sua composição básica está o dado "D" que são os fatos aos quais se recorre como fundamentos para as alegações, ou seja, é a base para a asserção original. Sem o dado não existe argumento. Ele é colocado de forma explícita. Conforme o desenrolar das convicções surgem garantias "G", as quais autorizam a passagem dos dados para a alegação, isto é, são afirmações hipotéticas que permitem a inferência. Sua função é 


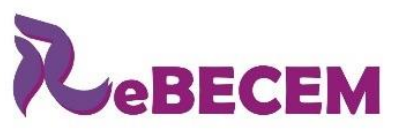

Revista Brasileira de Educação em

Ciências e Educação Matemática

DOI: https://doi.org/10.33238/ReBECEM.2021.v.5.n.1.26090

explanatória, procura registrar e autenticar as alegações postas. As garantias são tomadas implicitamente. Já a conclusão "C" são alegações que se procura justificar. Em um argumento simples os elementos fundamentais são o dado (D), a conclusão (C) e a garantia (G). É possível apresentar um argumento contando apenas com esses elementos, cuja estrutura básica é: "a partir de um dado D, já que G, então C".

Em alguns casos, o argumento pode ser mais emaranhado, contando com o apoio "A" que é outro aval para dar suporte à garantia e depende do contexto do campo de argumentação em questão. Ele deve ser retirado de uma informação básica e pode ser expresso com afirmações categóricas ou dado invocado em suporte direto. Os apoios têm origem bastante diversificada. Toulmin (2006) intitula campo-dependência a variabilidade do apoio das garantias.

Há ainda diferentes garantias as quais conferem distintos graus de força ao argumento, são os qualificadores modais "Q" que avigoram a declaração. Já os refutadores "R" revelam o imperativo de abandonar as garantias descartando sua autoridade por mostrar condições, invalidando-as. O qualificador "Q" é o elemento chave na avaliação de um argumento e o veredicto depende do sujeito e da comunidade de falantes que o avaliam. Apreciando a autoridade dos subsídios limitativos (R) e aprovativos (G e A), o qualificador amortece ou avigora a conclusão. A Figura 1 traz um diagrama visual do que foi citado, o arcabouço de um padrão para ponderar argumentos.

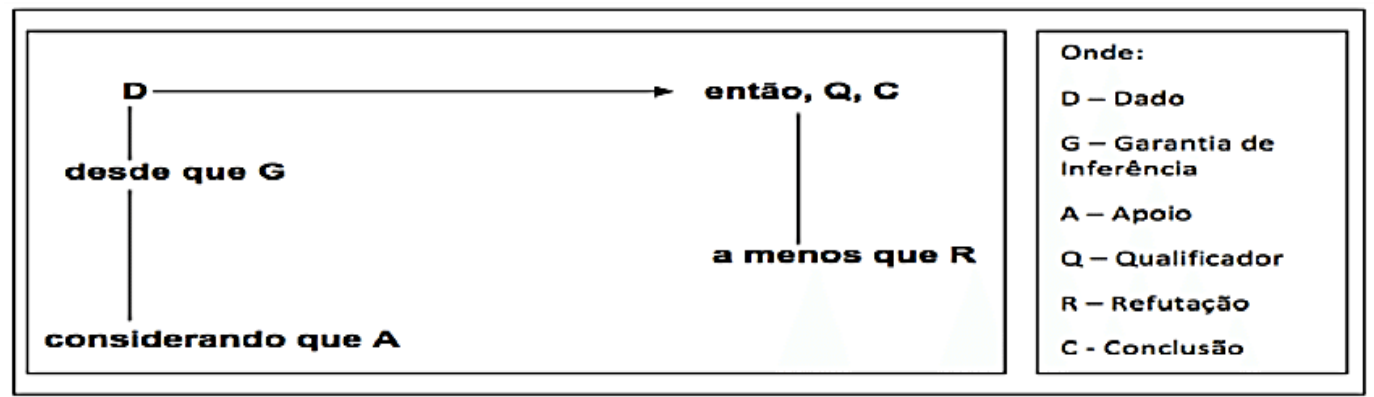

Figura 1: Padrão argumentativo de Toulmin Fonte: Toulmin (2006).

A seta na figura 1 indica a ligação entre os elementos que compõem a argumentação. Não se trata de um esquema engessado, pois admite versatilidade em sua disposição. Assim, abraça desde os argumentos mais simples aos mais complexos, e confere ao desenho praticidade em várias situações.

O desenvolvimento da argumentação está concatenado também às dimensões emocionais e sociais, tais particularidades não devem ser menosprezadas. As atitudes de alunos e professores, o ambiente e as condições em que esta será alavancada assumem 


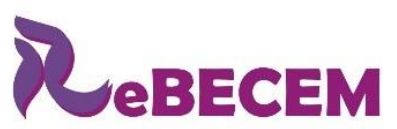

Revista Brasileira de Educação em

Ciências e Educação Matemática

DOI: https://doi.org/10.33238/ReBECEM.2021.v.5.n.1.26090

grande magnitude na trajetória e nas repercussões como já comentado anteriormente. Além disso, Maturana (1998) realça que a cognição é modelada pelas emoções, sendo a trajetória cognitiva do aprendiz direcionada pelos seus sentimentos mais do que pelos pensamentos. Deste modo, o pensamento inclui a razão e a emoção, compreende o ser humano e seu contexto como uma trama que se influenciam reciprocamente. Entende-se que a argumentação se relaciona às experiências dos estudantes que são produzidas a partir de suas vivências.

As demandas recentes requerem propostas didáticas atualizadas com o foco no exercício da cidadania. Navas (2010) ressalva que os sentimentos estudantis devem ser considerados durante o processo de desenvolvimento como cidadão. Coloca, por fim, o professor como parte medular para o alcance do amadurecimento cognitivo e da autonomia pelos discentes. Nessa resenha, a habilidade argumentativa assume lugar enfático, pois um cidadão participativo carece saber se situar em múltiplos e distintos momentos. $\mathrm{O}$ entusiasmo do aluno se conecta às características contextuais apresentadas pelos conteúdos, pois subsiste à conveniência do encontro por parte do estudante de um motivo para a construção de determinado conhecimento (PALMER, 2005).

Nesse sentido, Bellucco (2015) argumenta que a comunicação deve proporcionar a significação dos conceitos ao nível cognitivo e social. $\mathrm{O}$ autor adverte que a linguagem científica pode ter diferentes significados para as pessoas conforme sua interpretação particular. Esse fator amplia a reflexão sobre a aprendizagem enquanto participação na cultura científica. $\mathrm{O}$ aluno precisa atuar no processo de edificação dos conteúdos que, por sua vez, devem estar ligados aos conhecimentos habituais, contribuindo para a construção de saberes mais sistematizados.

Diversos pesquisadores defendem a ideia de que quando as necessidades psicológicas básicas do indivíduo (autonomia, competência, pertencimento) são satisfeitas o seu desempenho é melhor e este enfrenta com ânimo as circunstâncias desafiadoras (RYAN; POWELSON, 1991; RYAN; STILLER; LYNCH, 1994; REEVE; JANG, 2006). As necessidades psicológicas são próprias de cada indivíduo, e quando tais características psíquicas se articulam com os anseios e valores, as fontes de atividades intrínsecas de cada um são instituídas (CLEMENT, 2013).

Nessa perspectiva, cabe ao professor desenvolver recursos didáticos que cativem o interesse e motivação em realizar as atividades no âmbito escolar. Como citamos 
DOI: https://doi.org/10.33238/ReBECEM.2021.v.5.n.1.26090

previamente, o trabalho em equipe leva à aprendizagem colaborativa e à contextualização dos tópicos, as quais produzem significação dos conteúdos.

Numa circunstância de aprendizagem, a interação pedagógica centrada na argumentação mediante do diálogo proporciona sua (re)significação. A valorização dos posicionamentos discentes é essencial para que estes estejam dispostos a enfrentar as novidades com coragem. A ação de traduzir em palavras seus pensamentos estão incorporados no processo de desenvolvimento cognitivo do estudante. Para Vygotsky:

A relação entre o pensamento e a palavra é um processo vivo; o pensamento nasce através das palavras. Uma palavra desprovida de pensamento é uma coisa morta, e um pensamento não expresso por palavras permanece uma sombra. A relação entre eles não é, no entanto, algo já formado e constante; surge ao longo do desenvolvimento e também se modifica (VYGOTSKY,1989, p. 131).

A qualidade do argumento tem íntima relação com questões afetivas e com a alegria no ato de aprender. Elementos de ordem bastante particular, por exemplo, a timidez, ou gagueira, podem comprometer a disposição do aluno para participar das aulas. Perante essas colocações, fica notório que o desempenho estudantil excede o campo pedagógico e destaca-se a importância da ação docente ao agir com sabedoria a fim de que além de praticar metodologias relacionais, estas também sejam abrangentes, possibilitando o aprendizado de todos os envolvidos.

Qualificar a argumentação não é tarefa fácil diante da perplexidade das razões que a encerram. Contudo, conclui-se que um dos apanágios da argumentação é o desenvolvimento de capacidades intelectuais de expressão discursiva, tanto oral quanto escrita. Para adiante de questões pedagógicas vale ao docente contemplar o cidadão que deseja formar e nomear premissas em sua prática.

\section{Delineamento metodológico}

Este artigo originou-se de uma pesquisa de caráter qualitativo apresentando algumas características da pesquisa-ação, visto que se baseou na resolução de um problema prático, relacionado ao desenvolvimento da argumentação no ambiente do EI em aulas de Física e na produção de conhecimento pela professora pesquisadora que estava inserida diretamente no contexto investigado. De modo geral, buscava-se uma 


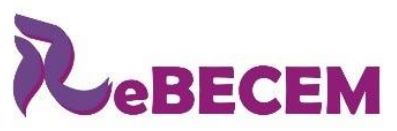

Revista Brasileira de Educação em

Ciências e Educação Matemática

DOI: https://doi.org/10.33238/ReBECEM.2021.v.5.n.1.26090

melhor qualidade para a interação professor/aluno com vistas à promoção da aprendizagem nas aulas de Física.

Na pesquisa-ação, para alcançar as metas propostas, faz-se necessário relacionar o conhecimento e a ação dos envolvidos (pesquisadores e sujeitos) no contexto pesquisado. Entende-se, ainda, a conexão entre a teoria e a prática, bem como o desenvolvimento da ação de forma coletiva, enquanto benéficas no sentido do engajamento em questões sociais relevantes.

De acordo com Thiollent (1985), esta integração propicia a ampliação do conhecimento do pesquisador, a reflexão das pessoas que participam do processo e possibilita ainda o debate sobre a temática em questão. Um dos objetivos da pesquisaação é criar subsídios para que os participantes sejam capazes de protagonizar.

Assumimos o duplo desafio de implementar práticas pedagógicas mais dialógicas associado ao de analisar criticamente o próprio trabalho, o que representa uma expectativa de aprimoramento profissional docente e, ao mesmo tempo, contribui para o desenvolvimento de competências pelos estudantes (MOURA; ASSIS, 2020).

Esta pesquisa foi desenvolvida em uma escola central da rede pública estadual, na cidade de Coromandel/MG. Participou do estudo uma turma de terceiro ano do ensino médio com 42 alunos. Os alunos incluídos na pesquisa foram envolvidos de acordo com sua disponibilidade/interesse em contribuir com os passos da mesma, seu período escolar e por trabalharem e vivenciarem o tema do estudo de caso da investigação.

O trabalho pedagógico acompanhado e investigado foi desenvolvido em cinco etapas. A primeira pressupôs refletir sobre o contexto em que o trabalho se originou, passando pelos objetivos de aprendizagem e a organização das ações e recursos. Posteriormente realizou-se a organização da sala em equipes, escolha dos temas e introdução do ensino por investigação. A próxima fase proporcionou uma maior integração entre professora/pesquisadora e alunos através da monitoria dos trabalhos desenvolvidos pessoal e/ou virtualmente. Na sequência aconteceu a apresentação de seminários pelos alunos sobre os temas trabalhados onde se destinou especial atenção para as questões de pesquisa. Finalmente relacionou-se a qualidade da argumentação apresentada ao ensino de física por investigação e a eficácia da metodologia aplicada.

A fonte de dados utilizada foi o diário da prática pedagógica (DPP) da professora pesquisadora. Nele foram registrados os principais aspectos observados e as impressões mais significativas. O DPP consiste em um documento pessoal onde o professor pode 


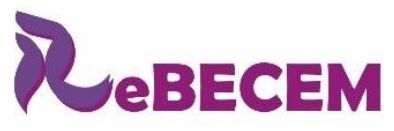

DOI: https://doi.org/10.33238/ReBECEM.2021.v.5.n.1.26090

externar seus pensamentos e percepções acerca do processo de ensino. Geralmente, os relatos trazem detalhes muito particulares que passariam despercebidos em outras técnicas de coleta de dados. O DPP retrata a experiência do educador na aplicação do seu planejamento e possibilita captar as causas de falhas e sucessos no processo de ensino. Nesse viés, o DPP caracteriza-se como instrumento de acompanhamento e avaliação crítico-reflexiva da prática pedagógica possibilitando reconstrução de ações e atribuindolhes razão e sentido (USTRA; PACCA; TERRAZZAN, 2016). Por conseguinte, revisita a figura do professor pesquisador remetendo não apenas a uma postura investigativa, mas também reflexiva oportunizando um crescimento profissional constante.

Os argumentos utilizados neste estudo foram extraídos das monitorias e dos seminários. Selecionou-se dois argumentos de cada grupo, que posteriormente, foram transcritos e analisados utilizando elementos próprios da metodologia adotada, para sua interpretação e compreensão. A Análise de Conteúdo (BARDIN, 2011) tem por finalidade explicar e sistematizar o teor da mensagem e seu significado por meio de deduções lógicas e justificadas tendo como referência sua origem e o contexto ou efeitos dessa mensagem. Seus principais objetivos são a diminuição das incertezas e o enriquecimento da leitura.

A partir dessa análise, foram configuradas as categorias que permitiram a classificação do material coletado e reunião desse por grupos de elementos sob um título comum em razão das características compartilhadas. A Análise de Conteúdo estabelece por inferência o conhecimento de índices invisíveis ao nível dos dados em bruto, visto que fornece informações suplementares ao leitor crítico de uma mensagem.

Finalmente, todo o material foi criteriosamente explorado e apresentado em texto dissertativo evidenciando os resultados obtidos tanto na aquisição de conhecimentos quanto em relação à transformação da prática pedagógica da professora pesquisadora.

\section{Resultados, discussão e análises}

Inicialmente, a professora pesquisadora conversou com a turma sobre os objetivos do projeto e estabeleceu parcerias, tanto no sentido de engajamento quanto de possibilidades de contestação e enriquecimento das ideias iniciais. A organização da classe em grupos ocorreu de forma bastante tranquila, sendo que a docente apenas fixou 
DOI: https://doi.org/10.33238/ReBECEM.2021.v.5.n.1.26090

o número de alunos por grupo deixando-os livres para se reunirem conforme suas afinidades, habilidades e conveniências.

A professora pesquisadora apresentou os critérios segundo os quais a investigação deveria acontecer. No diálogo com os estudantes enfatizou o trabalho em equipe como uma importante modalidade, dando a eles oportunidade de explorar seus potenciais de maneira confortável; por conseguinte deveria acontecer uma divisão de tarefas. Cada um poderia se responsabilizar por algo mais próximo às suas habilidades e, se não fosse o caso, contaria com ajuda dos demais.

A escolha do tema a ser pesquisado foi realizada mediante votação aberta. $\mathrm{O}$ estudo da Física Nuclear, tema escolhido, apresentava como objetivos gerais no livro didático, a compreensão da estrutura do núcleo atômico e os mecanismos explicativos do fenômeno da radioatividade. Além disso, pretendia-se levar os alunos a conhecerem os efeitos biológicos e ambientais das emissões radioativas e a raciocinar criticamente no que se refere ao uso da energia nuclear, considerando tanto os benefícios (que incluem aspectos de natureza econômica e social) quanto os riscos envolvidos nesses processos (TORRES et al., 2016). Conforme combinado no momento da escolha, o capítulo do livro foi dividido em subtópicos e estes sorteados entre os grupos.

\subsection{Os desdobramentos das atividades didáticas}

As atividades didáticas (AD) constituem-se na materialização de um conjugado de procedimentos peculiares favoráveis na circunstância de ensino-aprendizagem e, medeiam a relação entre os alunos e um tópico de estudo, contemplando aspectos sociais inseparáveis no ambiente pedagógico.

Para progressão das $\mathrm{AD}$, na presente pesquisa, não foi elaborado um roteiro fechado, já que a intenção era desenvolver a investigação a partir da problematização advinda do processo nos grupos de estudantes. E, reflexamente, optou-se por um modelo de aula desobstruído de regras convencionais, dando maior liberdade aos alunos através de um plano flexível. Obviamente, o fato de não haver uma receita para seguir, não excluiu a necessidade de estabelecer metas específicas para serem alcançadas ao longo da atividade. O Quadro 1 expõe sucintamente os fundamentos e intenções de cada AD realizada. 


\section{$R_{\text {eBECEM }}$}

Revista Brasileira de Educação em

Ciências e Educação Matemática

ISSN 2594-9179

DOI: https://doi.org/10.33238/ReBECEM.2021.v.5.n.1.26090

\begin{tabular}{|c|c|c|c|}
\hline $\begin{array}{l}\text { Atividades } \\
\text { didáticas }\end{array}$ & Situações-problema & $\begin{array}{l}\text { Objetivos específicos de } \\
\text { ensino }\end{array}$ & $\begin{array}{l}\text { Indicações para } \\
\text { aprofundamento } \\
\text { teórico }\end{array}$ \\
\hline $\begin{array}{l}\text { AD - } 1 \\
\text { Introdução - } \\
\text { Núcleo atômico }\end{array}$ & $\begin{array}{l}\text { Qual é a estrutura do } \\
\text { núcleo atômico? } \\
\text { Que contribuições a } \\
\text { Física Nuclear trouxe } \\
\text { para a sociedade no } \\
\text { século XX? }\end{array}$ & $\begin{array}{l}\text { Levar os alunos a } \\
\text { compreender a estrutura do } \\
\text { núcleo atômico. } \\
\text { Reconhecer a influência do } \\
\text { desenvolvimento da Física } \\
\text { Nuclear sobre o século XX. }\end{array}$ & $\begin{array}{l}\text { A radioatividade e a } \\
\text { história. } \\
\text { O Despertar da } \\
\text { radioatividade no século } \\
\text { XX. } \\
\text { Os modelos atômicos e } \\
\text { suas aplicações. }\end{array}$ \\
\hline $\begin{array}{l}\text { AD - } 2 \\
\text { Radioatividade - } \\
\text { Lei do } \\
\text { decaimento } \\
\text { radioativo }\end{array}$ & $\begin{array}{l}\text { Quais são as } \\
\text { características das } \\
\text { partículas alfa, beta e } \\
\text { gama e suas } \\
\text { aplicações? } \\
\text { Qual a diferença entre } \\
\text { meia-vida e vida } \\
\text { média? }\end{array}$ & $\begin{array}{l}\text { Conhecer o poder de } \\
\text { penetração de cada uma das } \\
\text { partículas e suas aplicações. } \\
\text { Entender a datação de } \\
\text { materiais por meio da } \\
\text { medição de carbono-14. } \\
\text { Definir e distinguir os } \\
\text { conceitos de meia-vida e } \\
\text { vida média. }\end{array}$ & $\begin{array}{l}\text { Vida média, meia vida e } \\
\text { constante radioativa. } \\
\text { Cálculo da meia-vida e } \\
\text { aplicações da } \\
\text { radioatividade. } \\
\text { Como é determinada a } \\
\text { idade de um fóssil? }\end{array}$ \\
\hline $\begin{array}{l}\text { AD - } \mathbf{3} \\
\text { Fissão nuclear e } \\
\text { fusão nuclear - } \\
\text { rejeitos } \\
\text { radioativos }\end{array}$ & $\begin{array}{l}\text { Quais os prós e contras } \\
\text { nos processos de fissão } \\
\text { e fusão nuclear? } \\
\text { Como minimizar os } \\
\text { perigos do lixo } \\
\text { radioativo? }\end{array}$ & $\begin{array}{l}\text { Entender os processos de } \\
\text { fissão e fusão nuclear e suas } \\
\text { aplicações. } \\
\text { Posicionar-se criticamente } \\
\text { sobre a construção de novas } \\
\text { usinas nucleares. }\end{array}$ & $\begin{array}{l}\text { Página oficial da } \\
\text { Comissão Nacional de } \\
\text { Energia Nuclear. } \\
\text { Operação de uma usina } \\
\text { nuclear/Tipos de } \\
\text { reatores. } \\
\text { A fusão nuclear } \\
\text { explicada: energia do } \\
\text { futuro? }\end{array}$ \\
\hline $\begin{array}{l}\text { AD-4 } \\
\text { Acidentes } \\
\text { nucleares e o uso } \\
\text { da } \\
\text { radioatividade }\end{array}$ & $\begin{array}{l}\text { Quais as normas } \\
\text { operacionais para } \\
\text { garantir a segurança e } \\
\text { eficiência na geração } \\
\text { de energia nuclear? } \\
\text { Quais as } \\
\text { consequências da } \\
\text { utilização bélica da } \\
\text { energia nuclear? } \\
\text { De que outras formas a } \\
\text { radioatividade é } \\
\text { utilizada? }\end{array}$ & $\begin{array}{l}\text { Destacar a importância das } \\
\text { normas legais sobre a } \\
\text { geração de energia nuclear. } \\
\text { Discutir o uso bélico da } \\
\text { energia nuclear. } \\
\text { Conhecer as aplicações da } \\
\text { energia nuclear. }\end{array}$ & $\begin{array}{l}\text { Página oficial da } \\
\text { Comissão Nacional de } \\
\text { Energia Nuclear. } \\
\text { Os maiores acidentes } \\
\text { nucleares da história. } \\
\text { Documentário Natgeo - } \\
\text { Hiroshima o dia } \\
\text { seguinte. } \\
\text { Usina nuclear por dentro. } \\
\text { Césio 137: } 30 \text { anos - } \\
\text { Documentário no } \\
\text { Fantástico - 03/09/2017. }\end{array}$ \\
\hline $\begin{array}{l}\text { AD-5 } \\
\text { Um pouco de } \\
\text { evolução estelar } \\
\text { - forças } \\
\text { fundamentais da } \\
\text { natureza }\end{array}$ & $\begin{array}{l}\text { Quais são as etapas do } \\
\text { desenvolvimento de } \\
\text { uma estrela? } \\
\text { Quais são os tipos de } \\
\text { forças que existem na } \\
\text { natureza? }\end{array}$ & $\begin{array}{l}\text { Conhecer as etapas de } \\
\text { desenvolvimento estelar. } \\
\text { Compreender as forças } \\
\text { fundamentais da natureza, } \\
\text { comparando suas } \\
\text { intensidades. }\end{array}$ & $\begin{array}{l}\text { De poeira estelar a } \\
\text { Supernovas: O ciclo das } \\
\text { estrelas. } \\
\text { Que as } 4 \text { forças } \\
\text { fundamentais estejam } \\
\text { com você! }\end{array}$ \\
\hline $\begin{array}{l}\text { AD-6 } \\
\text { Partículas } \\
\text { fundamentais da } \\
\text { matéria- } \\
\text { antimatéria e } \\
\text { Cosmologia }\end{array}$ & $\begin{array}{l}\text { Quais são as partículas } \\
\text { fundamentais da } \\
\text { matéria-antimatéria? } \\
\text { O que você sabe sobre } \\
\text { a origem e expansão } \\
\text { do universo? }\end{array}$ & $\begin{array}{l}\text { Conceituar matéria, } \\
\text { antimatéria. } \\
\text { Conhecer os estudos que } \\
\text { tentam explicar a origem e } \\
\text { expansão do universo. } \\
\text { Compreender o caráter } \\
\text { provisório da ciência. }\end{array}$ & $\begin{array}{l}\text { Estudos recentes em } \\
\text { revistas como Ciência } \\
\text { Hoje e Scientific } \\
\text { American Brasil } \\
\text { Unificando as forças da } \\
\text { natureza. } \\
\text { O universo elegante. }\end{array}$ \\
\hline
\end{tabular}

Quadro 1: Indicação geral das atividades didáticas implantadas

Fonte: elaborada pelos autores

Cada AD foi desenvolvida por um grupo e sua sucessão ocorreu

diferenciadamente conforme as reivindicações dos mesmos. A professora pesquisadora 


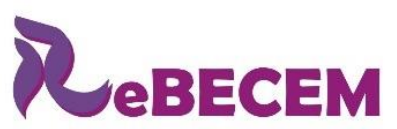

Revista Brasileira de Educação em

Ciências e Educação Matemática

DOI: https://doi.org/10.33238/ReBECEM.2021.v.5.n.1.26090

articulou ajuda ajustada às equipes buscando sincronia com o caminho seguido pelas mesmas, respeitando os progressos e dificuldades enfrentadas. Nesse aspecto, consideraram-se os conhecimentos prévios dos alunos provocando desafios para que os significados existentes fossem questionados repercutindo na (re)construção do conhecimento. Os recursos disponíveis foram apropriados às necessidades particulares de cada grupo de estudantes. Assim, as indicações para aprofundamento teórico, presentes no Quadro 1, foram apresentadas aos estudantes atendendo às dúvidas expostas por eles. Essas informações eram de fácil acesso e objetivavam conduzi-los ao entendimento mais amplo do conteúdo investigado. Em todas as equipes a exploração dessas informações foi bastante proveitosa tanto no sentido de fomentar o debate acerca da temática quanto de encontrar respostas viáveis para suas interrogações.

\subsection{Os dados do diário da prática pedagógica}

O DPP foi uma ferramenta importante no direcionamento das ações e nas introspecções realizadas neste estudo. Adiante encontra-se a descrição das anotações nele contidas.

Os alunos demonstraram grande interesse na investigação, a orientação inicial da docente foi que os grupos levantassem um problema de pesquisa dentro de seu tema. A problematização foi algo novo, visto que eles estavam habituados a receber as perguntas prontas. As interrogações elaboradas estavam nas redes virtuais e no próprio livro didático. Grande parte dos questionamentos diziam respeito a demandas teóricas da disciplina, pouco articuladas com as aplicações dos tópicos estudados ou a situações cotidianas.

Percebeu-se escassa habilidade no sentido de proferir a pergunta de forma objetiva. Assim, já que sua investigação seria conduzida pelos questionamentos propostos e estes ainda apresentavam baixa qualidade de arguição, fez-se necessária a intervenção docente no sentido de organizar/sintetizar as ideias por eles colocadas sem deixar essa falta de clareza se refletir na qualidade de sua argumentação nos seminários apresentados pelos grupos de alunos sobre suas respectivas AD. Ou seja, os alunos estavam em processo de adaptação à metodologia aplicada, mas a ajuda ajustada a eles concedida favoreceu a apropriação e a apresentação do problema por parte das equipes. O Quadro 2 apresenta os problemas formulados pelos grupos. 
\begin{tabular}{|l|l|}
\hline 1 & Quais os modelos atômicos conhecidos e suas funções? \\
\hline 2 & Como foram descobertas as antipartículas e quais os efeitos da sua aniquilação? \\
\hline 3 & Qual a importância dos processos de fissão e fusão nuclear para a humanidade? \\
\hline 4 & Porque acontecem os acidentes nucleares? \\
\hline 5 & Quais são as forças fundamentais da natureza e como elas nos afetam? \\
\hline 6 & O universo se expandirá para sempre? \\
\hline
\end{tabular}

Quadro 2: Problemas levantados pelos grupos

Fonte: elaborado pelos autores

\subsection{Grupo 1: Introdução à Física Nuclear e ao núcleo atômico}

Os aspectos históricos que impulsionaram o nascimento da Física Nuclear eram totalmente desconhecidos e causaram grande curiosidade. Os primeiros questionamentos foram em relação às motivações deste estudo e seus impactos sociais. Acerca do núcleo atômico havia conhecimentos oriundos das aulas de Química, no entanto, ao serem questionados sobre a finalidade e sustentação científica dos diversos modelos atômicos, os alunos ficavam completamente confusos. Apesar do grande número de perguntas e de ficar claro o esforço investigativo, a equipe apresentou dificuldade em levantar um problema de pesquisa, algo que fosse a meta principal do seu estudo.

Todos os componentes do grupo se envolveram na pesquisa e houve apoio mútuo. Como o elevado nível de abstração mostrou-se um obstáculo para eles, todos se empenharam na construção dos modelos atômicos com alimentos e na organização de slides para sintetizar e direcionar suas colocações. Tal estratégia chamou muito a atenção dos colegas, tornou seu seminário mais descontraído e dinamizou a interação entre o grupo e os demais alunos da turma. A Figura 2 representa a argumentação dos alunos durante a monitoria. A conclusão é inferida das falas dos alunos, como mostrado a seguir: 
DOI: https://doi.org/10.33238/ReBECEM.2021.v.5.n.1.26090

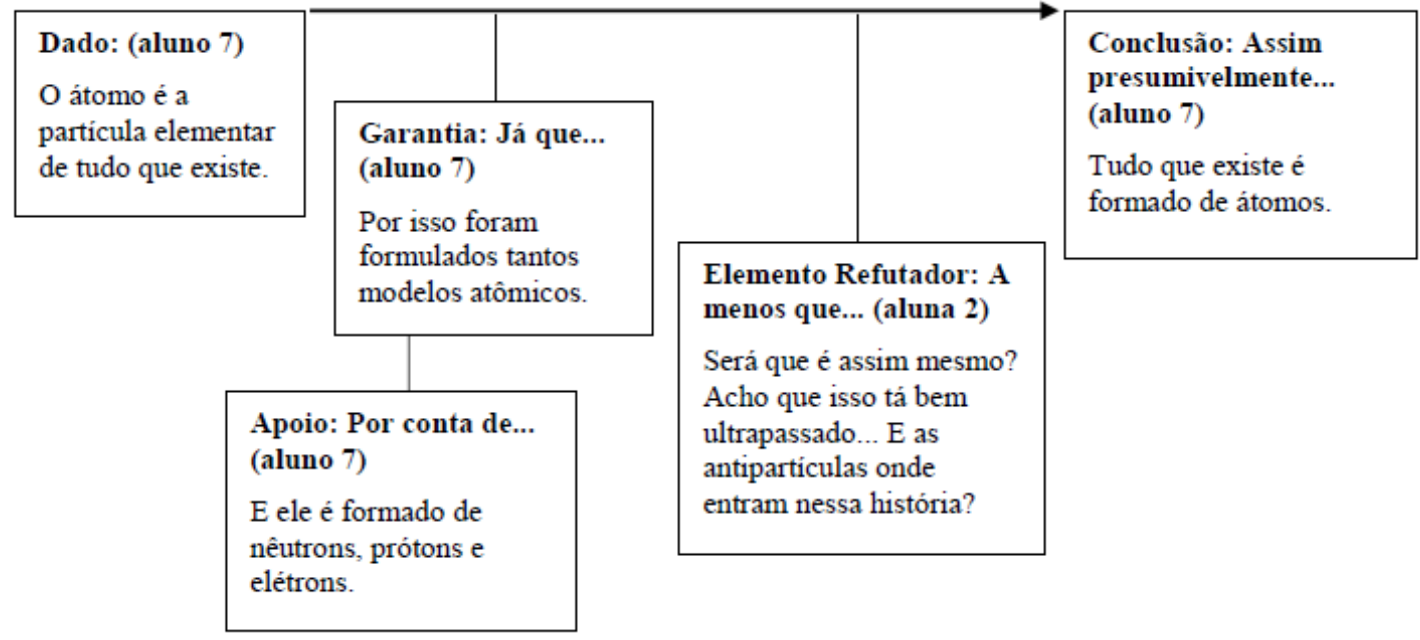

Figura 2: Exemplo de diálogo durante monitoria do Grupo 1 Fonte: Elaborada pelos autores.

Durante as monitorias, a conversa acontecia em um clima de confiança, quando os integrantes de cada grupo apresentavam suas justificativas para as escolhas de conceitos a serem utilizados na solução do problema. Dessa forma, as ideias eram apresentadas com vistas a construir os argumentos. No entanto, as garantias por eles vinculadas aos dados eram facilmente refutadas pelos próprios colegas, denunciando a necessidade de conhecimento mais aprofundado.

\subsection{Grupo 2: Radioatividade e lei do decaimento radioativo}

No começo os integrantes do grupo estavam muito perdidos e, antes mesmo da monitoria presencial, pediram ajuda para iniciar os trabalhos. Conversamos um pouco sobre o protagonismo de Marie Curie na descoberta dos raios x e sobre elementos radioativos, sem aprofundar nas características próprias de cada um deles, formulando questões para serem refletidas, como: qual a diferença entre os vários elementos radioativos? Existe radiação benéfica e maléfica? Em quais setores a radioatividade é utilizada? Quais são os níveis de radiação aceitáveis para os seres vivos?

Assim, eles iniciaram a busca de respostas a partir do livro didático e ampliaram a investigação com vídeo aulas, outros livros e em conteúdos da internet. A radiação e a meia vida dos materiais radioativos foram alvo de muita curiosidade e, a despeito da dificuldade inicial, esse grupo surpreendeu ao levantar o problema de pesquisa com maior prontidão. O grupo direcionou a pesquisa no sentido de encontrar aplicações dos conceitos estudados na vida prática. 


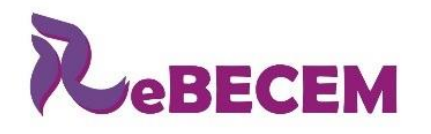

DOI: https://doi.org/10.33238/ReBECEM.2021.v.5.n.1.26090

\subsection{Grupo 3: Fissão nuclear, fusão nuclear e rejeito radioativo}

Os estudantes dessa equipe tentavam entender desde o princípio, os prós e os contras de cada um dos processos, destacando as diferenças entre eles. O nível de abstração das informações e a dificuldade de mensurar valores tão elevados ou tão pequenos para as grandezas físicas certamente estavam entre os principais obstáculos. Falar sobre os rejeitos radioativos contribuiu no sentido de pensar de modo bastante vivencial o tema, visto que estes afetam a saúde do homem e o meio ambiente trazendo grandes impactos se não tiverem o destino adequado. $\mathrm{O}$ grupo apresentou dificuldade em definir a questão de pesquisa.

Em todo tempo, relatavam as situações extremas em que ocorrem os processos, apresentaram muitos questionamentos sobre a fusão. E nessa vertente, buscaram abranger sobre os desafios da engenharia e da física para implantar o processo de fusão nas atividades humanas.

Evidenciou-se que o elevado nível de abstração do tema e a pouca familiaridade dos estudantes com os termos próprios da Física Moderna era um desafio adicional no desenvolvimento do processo argumentativo. Não obstante, entenderem algumas aplicações da temática, esta envolvia situações um tanto distantes da realidade próxima dos alunos.

As alegações dos estudantes apesar de conterem teor científico, traziam sempre um viés irreverente, utilizando gírias em suas falas, por vezes manifestando certo conflito entre ciência e senso comum.

Observa-se na argumentação indicada na Figura 3, um formato diferente do sugerido por Toulmin (2006). Os alunos não chegaram a uma conclusão sobre o processo de fusão nuclear. Os elementos básicos do argumento não estão caracterizados nesse diálogo de forma consistente; no entanto, destaca-se como ponto positivo a problematização e o teor científico das falas. Evidencia-se o processo investigativo no trabalho em equipe.

Os estudantes tentaram sustentar suas conclusões fazendo comparações a algo concreto. Em suas afirmações, demonstrava-se o distanciamento entre os conceitos aprendidos na Física Clássica com as novidades apresentadas pela Física Moderna, como apresentado na Figura 3. A argumentação entre eles acontecia de forma amistosa e o 


\section{$R_{\text {eBECEM }}$}

DOI: https://doi.org/10.33238/ReBECEM.2021.v.5.n.1.26090

respeito às opiniões diferentes não descartou persistência na sustentação do seu ponto de vista.

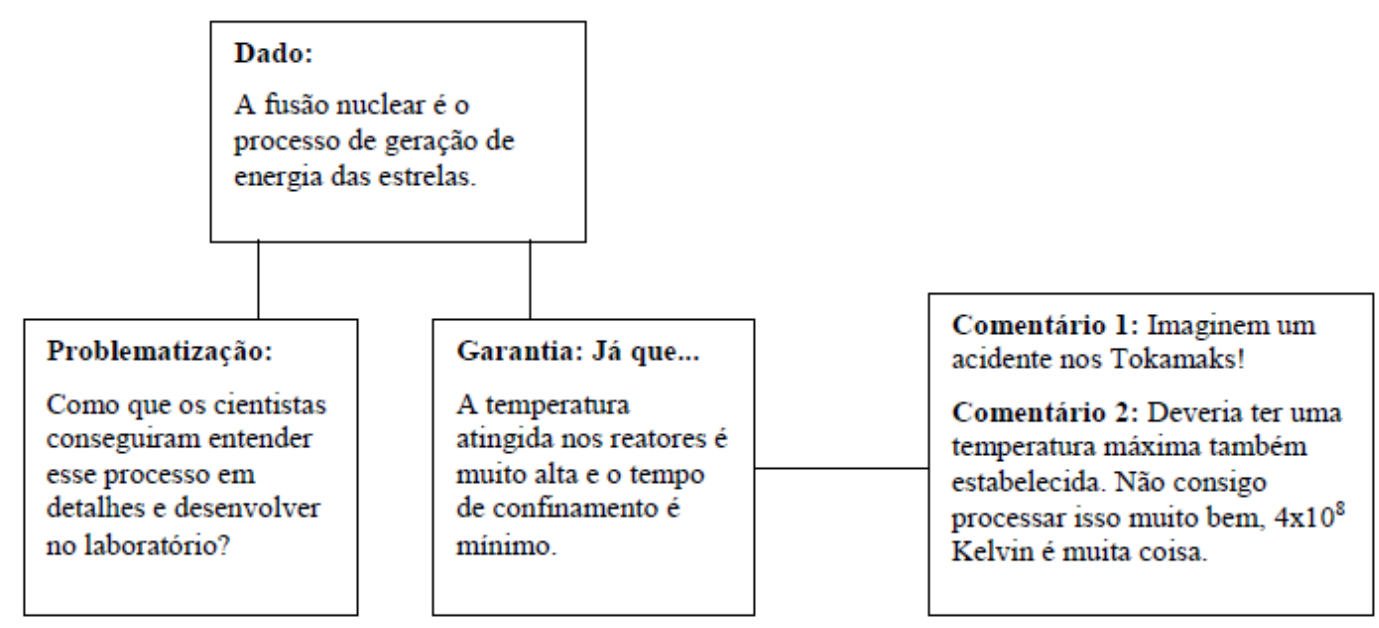

Figura 3: Exemplo de diálogo durante monitoria do Grupo 3

Fonte: Elaborada pelos autores.

\subsection{Grupo 4: Acidentes nucleares e o uso da radioatividade}

Os discentes logo perceberam que para além das questões científicas, esse tema envolve questões legais/normativas e sociais. Alguns integrantes da equipe comentaram o acidente ocorrido em Goiânia decorrente do contato indevido de algumas pessoas com Césio 137, eles conheciam os fatos de forma bastante superficial e se espantaram com a diferença de contexto em relação aos demais acidentes ocorridos.

O grupo ficou dividido entre várias questões de pesquisa. Mas, a indagação girou em torno de entender as causas dos acidentes e até mesmo as falhas das autoridades quando retarda a emissão de informações à população envolvida.

Como fator de destaque os estudantes aprofundaram a pesquisa sobre as aplicações da radioatividade na medicina. Fizeram vários questionamentos sobre o melhor destino para os rejeitos radioativos e ainda sobre os tipos de acidentes e suas causas. A utilização da energia nuclear no Brasil também foi alvo de debate. Assim, proporcionou a reflexão acerca dos perigos e benefícios trazidos pela radioatividade. A equipe conseguiu constatar as influências políticas e sociais no âmbito científico e apresentou aos colegas um vídeo muito interessante. 


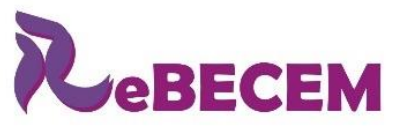

DOI: https://doi.org/10.33238/ReBECEM.2021.v.5.n.1.26090

5.7 Grupo 5: Um pouco de evolução estelar e das forças fundamentais da natureza

O grupo responsável pela $\mathrm{AD} 5$ apesar de ter questionamentos interessantes apresentou pouca objetividade colocando as ideias de forma bastante obtusa. Aqui estão algumas interpelações consideradas: "É possível comparar o ciclo de vida dos seres humanos e das estrelas, considerando os processos químicos estelares e humanos? Porque existem vários tipos de estrelas? As forças fundamentais da natureza se relacionam entre si?" Eles apresentaram dificuldade de traduzir em palavras sua pergunta de pesquisa. A intervenção da professora foi mais no sentido de sintetizar suas afirmações sem modificar a essência e, ao mesmo tempo direcionar a investigação.

Os integrantes da equipe articularam os conceitos já estudados na Física Clássica com os da Física Moderna e fizeram a síntese das informações coletadas em diferentes fontes. O maior repto dos alunos foi compreender a força nuclear fraca, devido à conexão com conceitos próprios da física moderna (decaimento beta, quarks e léptons). Comentaram ainda, sobre a dificuldade de entender a linguagem científica com muitos conceitos novos.

Em seus relatos, sempre destacavam a complexidade do tema apresentado atrelado a um elevado nível de detalhamento nas informações. Assim, uma das objeções desse grupo foi encontrar informações que estivessem em seu nível de entendimento. No entanto, todas as suas falas durante o seminário foram exemplificadas e conectadas com exemplos cotidianos.

\subsection{Grupo 6: Partículas fundamentais de matéria-antimatéria e cosmologia}

Os discentes detectaram interfaces da Física, Química, Biologia e tal articulação tornou a investigação mais instigante. Entre os grupos de alunos que desenvolveram as $\mathrm{AD}$, esse foi o mais questionador e ao longo do estudo foi possível perceber que ainda há questões inconclusas e várias especulações nesse campo. A pergunta que os orientou na pesquisa foi: O universo se expandirá para sempre?

A equipe ficou meio confusa com a infinidade de informações disponíveis. A falta de comprovação científica e mesmo a abundância de questionamentos acerca das teorias já existentes potencializaram as dúvidas no processo investigativo. Todavia, o grupo 


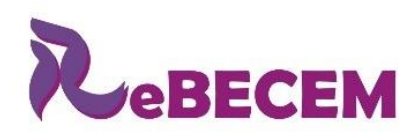

Revista Brasileira de Educação em

Ciências e Educação Matemática

DOI: https://doi.org/10.33238/ReBECEM.2021.v.5.n.1.26090

percebeu e conseguiu transmitir para a turma o caráter provisório da ciência, bem como entendeu de acordo com seu nível de maturidade a forma como se faz Ciência.

No seminário apresentado referente da $\mathrm{AD}$ 6, os estudantes empregaram uma analogia bastante simples com um balão mostrando a expansão do universo. E apresentaram aos colegas o resultado de pesquisas realizadas no jornal New York Times e na revista Science News usando a estratégia de autoridade (fala de cientistas renomados na atualidade) em sua argumentação.

\subsection{Composição das categorias e análise dos dados}

As categorias foram propostas a fim de ressaltar peculiaridades tanto na constituição do argumento quanto em questões pedagógicas primordiais voltada à qualidade do ato pedagógico. O processo de categorização adotado no estudo foi o acervo, visto que não havia categorias pré-estabelecidas. Essas são decorrentes da qualificação analógica e progressiva dos elementos e estão apresentadas no Quadro 3. As categorias 1, 2 e 3 dirigem nossa atenção para o conteúdo utilizado na construção do argumento, enquanto as categorias 4, 5 e 6 estão proferidas a fim de observar sua estrutura.

\begin{tabular}{|l|l|c|}
\hline \multicolumn{1}{|c|}{ Categorias } & Nível \\
\hline 1 & $\begin{array}{l}\text { O aluno apresenta em sua fala informações com teor científico considerável quando } \\
\text { comparado às referências bibliográficas acessadas durante o processo investigativo } \\
\text { e aponta aplicações práticas dos conceitos físicos abordados. }\end{array}$ & 3 \\
\hline 2 & $\begin{array}{l}\text { O aluno concede informações científicas condizentes com as pesquisas realizadas e } \\
\text { as apresenta de forma contextualizada. No entanto, não demonstra a utilidade } \\
\text { rotineira dos tópicos trabalhados. }\end{array}$ & 2 \\
\hline 3 & $\begin{array}{l}\text { O aluno profere informações que contém conhecimento científico, contudo as expõe } \\
\text { sem contextualização e funcionalidade. }\end{array}$ & 1 \\
\hline 4 & $\begin{array}{l}\text { Argumento simples - O aluno organiza seu ponto de vista utilizando os elementos } \\
\text { básicos do TAP (dado, garantia e conclusão). }\end{array}$ & 1 \\
\hline 5 & $\begin{array}{l}\text { Argumento com nível mediano - O aluno emprega um elemento acessório do TAP } \\
\text { na formação do seu argumento (apoio, qualificador modal ou elemento refutador) } \\
\text { ou apresenta mais de uma garantia para suas alegações. }\end{array}$ & 2 \\
\hline 6 & $\begin{array}{l}\text { Argumento mais complexo - O aluno apresenta mais de um elemento acessório na } \\
\text { estrutura do argumento, interligados coerentemente manifestando raciocínio lógico } \\
\text { e habilidade na elaboração de ideias. }\end{array}$ & 3 \\
\hline
\end{tabular}

Quadro 3: Categorias de análise

Fonte: elaborado pelos autores.

As categorias indicam a trajetória dos estudantes no EI apontando a transposição do senso comum para os conhecimentos científicos. Ao relacioná-los a contextos os quais lhes são familiares, nota-se que sua atividade seguiu uma linha bastante significativa conectando teoria e prática. 
DOI: https://doi.org/10.33238/ReBECEM.2021.v.5.n.1.26090

Em relação à avaliação, os diferentes níveis de desenvolvimento argumentativo evidenciados nas categorias devem ser confrontados com as características individuais de cada estudante. Por exemplo, um argumento mediano para um estudante tímido, resistente a falar em público, representou maior progresso que para um estudante extrovertido.

As categorias estabelecem um elo entre as observações realizadas em nosso estudo e o aporte teórico utilizado. De certa forma, elas denunciam os resultados alcançados bem como as melhorias que devem ser empreendidas em oportunidades futuras. O nível nessa conjuntura cumpre a função de associar aspectos estruturais e pedagógicos, contribuindo para a identificação de características específicas na argumentação dos estudantes.

Nas análises que incluíram a interação dos estudantes durante as monitorias coordenadas pela professora pesquisadora, observou-se que $25 \%$ dos argumentos, apesar de apresentar uma estrutura mediana eram fracos por possuir conhecimento científico descontextualizado e sem funcionalidade. $8,3 \%$ eram bons, pois apresentaram estrutura mediana e conhecimento científico contextualizado; $50 \%$ dos argumentos foram considerados ótimos, sendo que destes $41,7 \%$ eram medianos quanto à estrutura, contudo apresentaram conhecimento científico contextualizado e com aplicações práticas; e 8,3\% apresentaram estrutura complexa e conhecimento científico contextualizado. $16,7 \%$ foram considerados excelentes por possuírem maior grau de complexidade e ainda aportarem conhecimentos científicos contextualizados e com aplicações práticas. A distribuição das análises dos argumentos estudantis encontra-se na Figura 4:

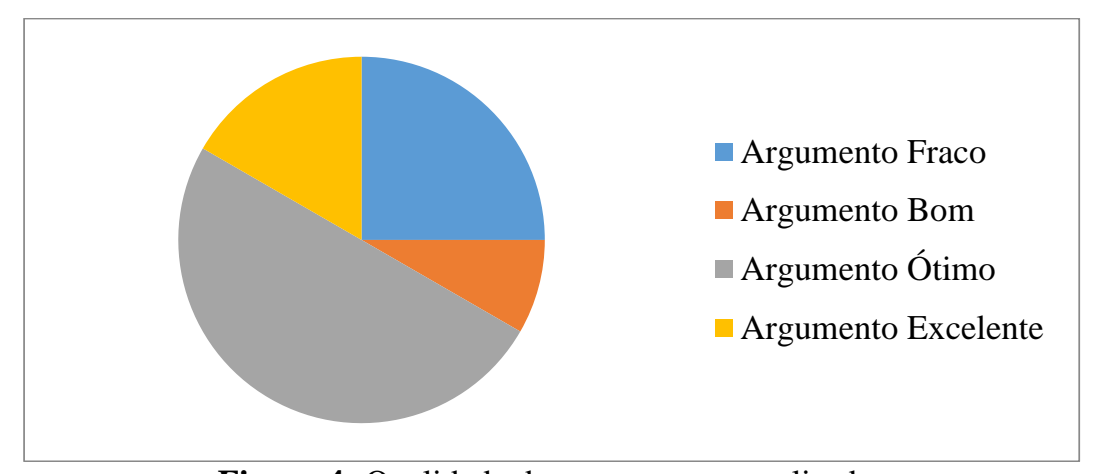

Figura 4: Qualidade dos argumentos analisados Fonte: Elaborado pelos autores.

Sobreleva-se que não houve argumentos simples, o que de certa forma evidenciou o esforço dos estudantes em apresentar seus pontos de vista com uma quantidade extra de garantias aos ouvintes. Assim, nenhum argumento se deteve apenas aos elementos básicos do TAP. 


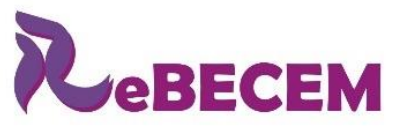

DOI: https://doi.org/10.33238/ReBECEM.2021.v.5.n.1.26090

Outro ponto importante a ser ressaltado, é a evolução dos estudantes em relação às argumentações manifestadas nas monitorias. Destacou-se a ação dialógica da docente com a turma no EI como uma possível explicação para a elaboração de argumentos mais aperfeiçoados por parte dos alunos. Destarte, todos apresentaram elementos acessórios em seus argumentos, sendo que $75 \%$ dos argumentos obtiveram estrutura mediana e $25 \%$ estrutura complexa.

Ao enfatizar as questões epistêmicas associadas aos conceitos, definições, contextualização e aplicação dos tópicos estudados, 58,3\% dos argumentos apresentaram os temas de forma a reconhecer o uso prático e circunstancial dos subsídios obtidos; $16,7 \%$ colocaram os conhecimentos científicos contextualizados e sem funcionalidade; e $25 \%$ apenas abordaram os conhecimentos científicos sem contextualizar ou apontar uma utilidade para eles.

Em linhas gerais, identificaram-se avanços na capacidade argumentativa dos estudantes advindos da metodologia desenvolvida. E apesar de entreverem-se ajustes necessários ao seu aprimoramento, a aprendizagem pode ser salientada nas análises efetuadas através dos registros no DPP que incluiu dados de todas as monitorias.

\section{Conclusão}

Durante a execução do estudo em foco, percebeu-se que metodologias abertas, flexíveis, sensíveis à formação humana e ao pensamento complexo são viáveis. Compreendeu-se também o quanto a postura do professor frente à turma, reflete-se na atitude participativa dos estudantes, sendo essencial para o êxito no processo educacional. Portanto, a maneira como a professora pesquisadora se entrosou com a turma foi determinante. Coube à professora estabelecer um convívio cooperativo propiciando uma aprendizagem colaborativa. Ela não é a dona da verdade e mostrou aos alunos a importância de trabalharem juntos na construção do saber. Esse endosso preceptoral fez com que eles se sentissem capazes e isso facilitou a comunicação expandindo as possibilidades de conquistas valorosas.

Outrossim, a argumentação dos alunos no ensino de Física por investigação ocorreu de forma bastante livre, porque eles entenderam a significância de suas afirmações, não obstante elas estivessem incorretas, poderiam contribuir para o alcance 
DOI: https://doi.org/10.33238/ReBECEM.2021.v.5.n.1.26090

do conhecimento científico. Os envolvidos, ao vislumbrarem as revoluções científicas, perceberam que a ciência não se prende a verdades incondicionais, mas se constitui numa grande jornada onde novas descobertas vão surgindo e enriquecendo ou descartando aquelas até então conhecidas.

Sucintamente, pode-se filtrar que, na argumentação, a interatividade entre os envolvidos faz-se importante no seu progresso, constituindo-se em uma ação dinâmica de formação humana e cognição singularizada. Vale ressaltar nosso interesse na argumentação (processo) e não apenas no argumento (produto), destacando-se a seleção de hipóteses e ideias organizadas pela intervenção do professor que fomenta procedimento específico para cada situação legitimando o conhecimento argumentativo e consolidando com efetividade a formação de sujeitos críticos, dando sustentabilidade de conteúdo e singularizando cada colocação individual no grupo.

Compreendemos que trabalhos no âmbito da pesquisa-ação mostram-se eficazes para provocar uma discussão/reflexão sobre a prática docente a fim de compreendê-la e agenciar o progresso do ensino de física enquanto campo da docência, mas sobretudo, enquanto lugar da pesquisa do próprio professor. Desta maneira, o objetivo de refletir sobre a docência e a importância de uma proposta didática mais dialógica teve êxito. Observou-se que, não obstante os intentos impetrados ainda existem vários aspectos da argumentação a serem trabalhados em atividades investigativas. Ensinar é uma aventura e não nos dá a opção de permanecermos estáticos. Aceitar os tropeços, e ajustar o roteiro faz parte de uma caminhada bem sucedida.

\section{Referências}

BARDIN, L. Análise de conteúdo. Lisboa: Edições 70, 2011.

BELLUCO, A. Argumentação Matemática em aulas investigativas de Física. Tese de Doutorado, Programa de Pós-Graduação em Educação, Universidade de São Paulo, São Paulo, 2015.

CLEMENT, L. Autoderterminação e Ensino por Investigação: construindo elementos para promoção da autonomia em Aulas de Física. Tese de Doutorado em Educação Científica e Tecnológica, Universidade Federal de Santa Catarina, Florianópolis, 2013. 
DOI: https://doi.org/10.33238/ReBECEM.2021.v.5.n.1.26090

CORREIA, D.; DECIAN, E.; SAUERWEIN, I. P. S. Leitura e argumentação: potencialidades do uso de textos de divulgação científica em aulas de Física do ensino médio. Ciência e Educação, Bauru, v. 23, n. 4, p. 1017-1034, out./dez., 2017.

COSTA, A. Desenvolver a capacidade de argumentação dos estudantes: um objetivo pedagógico fundamental. Revista Iberoamericana de Educación, Madri, v. 46, n. 5, p. 1-8, jun., 2008.

DRIVER, R.; NEWTON, P.; OSBORNE, J. Establishing the norms of scientific argumentation in classrooms. Science Education, v. 84, n. 3, p. 287-312, abr., 2000.

DUSCHL, R. A.; OSBORNE, J. Supporting and promoting argumentation discourse in science education. Studies in Science Education, 38, p. 39-72, mar., 2002.

FERRAZ, A. T. Propósitos epistêmicos para a promoção da argumentação em aulas investigativas de física. 2015. 175 f. Dissertação de Mestrado em Ensino de Ciências, Universidade de São Paulo, São Paulo, 2015.

MALACARNE, V.; STRIEDER, D. M.; LIMA, D. F. Ética, Ciência e formação de professores: a escola na sociedade contemporânea. Ensaio Pesquisa em Educação em Ciências, Belo Horizonte, v. 13, n. 3, p. 51-66, 2011.

MATURANA, H. Emoções e linguagem na educação e na política. $1^{\mathrm{a}}$ ed. Belo Horizonte: UFMG, 1998.

MONTEIRO, S. B. Epistemologia da prática: o professor reflexivo e a pesquisa colaborativa. In: GHEDIN, E.; PIMENTA, S. O professor reflexivo no Brasil: gênese e crítica de um conceito. $3^{\mathrm{a}}$ ed. São Paulo: Cortez, p. 111-128, 2005.

MORAES, M. C.; NAVAS, J. M. B. (Org.). Complexidade e transdisciplinaridade em educação: teoria e prática docente. $1^{\mathrm{a}}$ ed. Rio de Janeiro: Wak, 2010.

MOURA, A. C.; ASSIS, A. Ensino de física térmica: ciclos de reflexão de um professor de física sobre a sua prática pedagógica. Caderno Brasileiro de Ensino de Física, Florianópolis, v. 37, n. 2, p. 593-618, ago., 2020.

NAVAS, J. M. B. Didáctica deconstructiva y complejidad: algunos princípios. In: MORAES, M. C; NAVAS, J. M. B. (Org.). Complexidade e transdisciplinaridade em educação: teoria e prática docente. $1^{\text {a }}$ ed., Rio de Janeiro: Wak, 2010.

PALMER, D. A Motivational view of constructivist-informed teaching. International Journal of Science Education, Mandsaur, v. 27, n. 15, p. 1853-1881, dez., 2005. 
DOI: https://doi.org/10.33238/ReBECEM.2021.v.5.n.1.26090

REEVE, J.; JANG, H. What teachers say and do to support students'autonomy during a learning activity. Journal of educational Psychology, Washington, v. 98, n. 1, p. 209-218, fev., 2006.

RYAN, R. M.; POWELSON, C. L. Autonomy and relatedness as fundamental to motivation and education. Journal of Experimental Education, v. 60, n. 1, p. 49-66, 1991.

RYAN, R. M.; STILLER, J.; LYNCH, J. H. Representations of relationships to teachers, parents, and friends as predictors of academic motivation and self-esteem. Journal of Early Adolescence, v. 14, n. 2, p. 226-249, mai., 1994.

SÁ, L. P.; QUEIROZ, S. L. Argumentação no ensino de ciências: contexto brasileiro. Ensaio Pesquisa em Educação em Ciências, Belo Horizonte, v. 1. 13, n. 2, p. 13-30, mai./ago., 2011.

SCARPA, D. L.; SASSERON, L. H.; SILVA, M. B. O Ensino por investigação e a argumentação em aulas de Ciências Naturais. Tópicos Educacionais, Recife, v. 23, n. 1, p. 7 27, jan./jun., 2017.

THIOLLENT, M. Metodologia da Pesquisa-Ação. 5 a ed. São Paulo: Cortez, 1985.

TORRES, C. M. A.; FERRARO, N. G.; SOARES, P. A. T.; PENTEADO, P. C. M. Física: Ciência e Tecnologia, 4. ed. São Paulo: Moderna, 2016.

TOULMIN, S. E. Os usos do argumento. São Paulo: Martins Fontes, 2. ed., 2006.

USTRA, S. R. V.; PACCA, J. L. A.; TERRAZZAN, E. A. Diários da prática pedagógica: pressupostos e contribuições para uma formação continuada emancipatória. In: GÜLLICH, R. I. C.; HERMEL, E. E. S. (Org.). Educação em Ciências e Matemática: pesquisa e formação de professores. Chapecó: UFFS, p. 35-57, 2016.

VYGOTSKY, L. S. Pensamento e linguagem. Trad. Jefferson Luiz Camargo. 2 a ed. São Paulo: Martin Fontes, 1989.

ZÔMPERO, A. F.; LABURÚ, C. E. Atividades investigativas no ensino de ciências: Aspectos históricos e diferentes abordagens. Ensaio: Pesquisa em Educação em Ciências, Belo Horizonte, v. 13, n. 3, p. 67-80, set./dez., 2011.

Recebido em: 15 de outubro de 2020

Aceito em: 7 de abril de 2021 